\title{
ОСОБЕННОСТИ ЗДОРОВЬЯ И ВОЗРАСТНАЯ СТРУКТУРА РОССИЙСКИХ РАБОЧИХ - ТРАДИЦИИ ПРОТИВ ИЗМЕНЕНИЙ
}

\begin{abstract}
В статье на материалах 25-й волны РМЭЗ НИУ ВШЭ (2016 г.) рассматривается физиологический ресурс рабочих, операционализированный через показатели возраста и состояния здоровья. Анализируется соотношение традиций (в частности, предпочтений при выборе молодежью типа деятельности) и изменений. Показано, что возрастная структура российских рабочих воспроизводится и практически совпадает с возрастной структурой работающего населения страны в целом. Миф о том, что молодежь не хочет «идти в рабочие» обусловлен высокой долей среди молодых рабочих неофициальной занятости, в силу чего значительная их часть не попадает в систему статистического учета. В то же время в последние годы наметились изменения - среди молодежи до 25 лет профессия продавца стала популярнее рабочих профессий. Продемонстрировано, что российские рабочие гетерогенная по состоянию здоровья профессиональная группа. Если квалифицированные рабочие характеризуются хорошими показателями здоровья, то работники неквалифицированного физического труда обладают не просто наихудшими показателями здоровья из всех профессиональных групп, но и наиболее ярко выраженной тенденцией его ухудшения с возрастом. Выделены три группы работников: полностью здоровые, с наличием отдельных проблем со здоровьем и имеющие множественные и серьезные проблемы со здоровьем. Итоговый вывод статьи заключается в том, что физиологический ресурс квалифицированных рабочих в России в настоящее время достаточен для того, чтобы можно было говорить об их способности выполнять задачи, которые могут встать в случае интенсивной технологической перестройки экономики. В то же время в силу возможных технологических изменений в области занятости рабочих,
\end{abstract}

Наталья Евгеньевна Тихонова - д.с. н., профессор-исследователь, Национальный исследовательский университет «Высшая школа экономики»; главный научный сотрудник, Институт социологии ФНИСЦ РАН, Москва, Россия. Электронная почта: ntihonova@hse.ru 
и в экономике в целом, формируются серьезные вызовы для государственной социальной политики, без адекватного ответа на которые невозможно обеспечить устойчивое социально-экономическое развитие страны в среднесрочной перспективе.

Ключевые слова: рабочие, здоровье, возрастная структура, человеческий потенциал, человеческий капитал, традиции

DOI: 10.17323/727-0634-2018-16-2-311-326

Сложная экономическая ситуация, в которой оказалась Россия, а также взятый ею курс на импортозамещение актуализировали необходимость изучения рабочего класса как одного из ключевых субъектов, призванных повысить эффективность функционирования реального сектора экономики страны. Огромную роль в способности российских рабочих справиться с задачами, которые возлагаются на них в этой связи, играет их человеческий потенциал. Он формируется в определенной институциальной среде, а главный инструмент, с помощью которого государство может влиять на качество человеческого потенциала,- социальная политика.

Социальная политика изменила свою направленность и превратилась сегодня из способа помочь наиболее нуждающимся, как это было в начале $\mathrm{XX}$ в., в важнейшее звено обеспечения устойчивого социального-экономического развития (Шкаратан и др. 2003; Baldock et al. 2007). Это нашло отражение в разработке разного рода инструментов для измерения качества человеческого потенциала, в частности применяемого во всем мире Индекса развития человеческого потенциала (с 2010 г.- Индекса человеческого развития). Однако выработка такой политики предполагает понимание ситуации с состоянием человеческого потенциала различных социальных групп, в частности, их возрастной структуры и состояния здоровья.

В полной мере вышесказанное относится и к такой группе как рабочие, жизнь которых зачастую считается монотонным повторением «традиций». Но те изменения, которые происходят в последние годы в сфере выбора молодежью рабочих профессий, отношения рабочих-мужчин к своему здоровью, сдвигов в возрастной структуре рабочих дополнительно актуализируют проблематику человеческого потенциала представителей данной группы. В этой статье конфликт между накатанной профессиональной и жизненной траекторией (традициями) и новыми тенденциями в сфере труда рассматривается на данных о человеческом потенциале занятых в рабочих профессиях россиян.

\section{Теоретико-методологическая}

\section{и эмпирическая база исследования}

Учитывая растущую роль рабочих в российской экономике, внимание к ним в последние годы активизировалось (Митягина 2014; Кремнева, 
Лукьянова 2015; Тартаковская, Ваньке 2016; Каравай 2016; Латова 2017; Тихонова, Каравай 2017). В то же время состояние их здоровья и тесно связанная с ним возрастная структура по-прежнему остаются вне поля зрения социологической науки, кроме исследований «public health» (см.: Авдошина 2003), хотя здоровье занятого населения или населения в целом регулярно становится предметом анализа социологов (Назарова 2007; Кузьмич 2012). К числу немногих исключений в этой области можно отнести работы Галины Бессокирной (Бессокирная 2013) и Анастасии Каравай (Каравай 2016), но и здесь здоровье не рассматривается как элемент человеческого потенциала. В то же время оно прямо влияет не только на способность человека к труду, но и на его возможности и желание осваивать новые знания и практики, без чего невозможно говорить о качестве человеческого потенциала.

Сразу подчеркнем - человеческий потенциал рассматривается нами как более широкое понятие, чем человеческий капитал. Напомним, что классические концепции человеческого капитала (Mincer 1958; Becker 1962) интерпретируют его как совокупность знаний и навыков (компетенций) индивида, которые проявляются в количестве лет его обучения и трудовом стаже. В этих работах расходы на образование считаются инвестициями, которые приносят «отдачу» владельцу человеческого капитала в виде как материальных, прежде всего денежных, так и нематериальных благ.

Наряду с классической традицией существует иная интерпретация человеческого капитала, при которой это понятие включает в себя и другие характеристики человека как работника (Sen 1999; Заславская 2002). Для описания человеческого капитала в такой расширительной трактовке используется понятие «человеческий потенциал», описывающий влияющие на эффективность труда работника мировоззренческие и поведенческие особенности, а также его физиологический ресурс. Подробный обзор эволюции понятий «человеческий капитал» и «человеческий потенциал» уже проводился в российской научной литературе (Соболева 2009; Плискевич 2012; Аникин 2017).

Эта концепция человеческого потенциала стала основой данного исследования. Эмпирической базой послужили данные репрезентативной части 25-й волны «Российского мониторинга экономического положения и здоровья населения НИУ ВШЭ (RLMS-HSE)», проходившей в октябре 2016 - январе 2017 гг. Численность выборки, репрезентирующей население страны в целом, составила 12554 человека, в том числе 5351 работающих, из которых 1768 человек составляли рабочиеㄹ.

В отраслевом разрезе представленность рабочих в этой волне очень широка - 30 отраслей. Однако чаще всего рабочие заняты на транспорте

\footnotetext{
${ }^{1}$ В качестве рабочих в рамках РМЭЗ НИУ ВШЭ рассматриваются представители 7-го, 8-го и 9-го классов согласно классификатору профессий ISCO-08.
} 
и в связи (15,3\% всех рабочих), в строительстве $(15,1 \%)$ и в торговле $(14,7 \%)$. С точки зрения форм собственности, предприятия, где заняты рабочие, относились в основном к частному сектору (57,9\%), хотя довольно значительная часть рабочих трудилась на государственных предприятиях или предприятиях с государственным участием (30,4\%). Остальные заняты на кооперативных предприятиях, предприятиях с участием иностранного капитала. Стоит отметить, что 41,3\% рабочих в использованном нами массиве заняты на предприятиях с численностью работающих менее 100 человек, развернутая статистическая отчетность по кадровому составу которых предприятиями в статистические службы страны не сдается, поэтому информация по ним, включенная в наш анализ, представляет особый интерес.

\section{Возрастная структура российских рабочих}

Традиционное распределение предпочтений при выборе профессий среди россиян на протяжении поколений и его изменения в молодом поколении ярко прослеживается в возрастной структуре занятых. Поэтому анализ физиологического ресурса российских рабочих как элемента их человеческого потенциала уместно начать с характеристики их возрастной структуры: она очень близка к возрастной структуре работающего населения страны в целом (табл. 1). Возрастные диспропорции наблюдаются только у неквалифицированных рабочих, под которыми мы имеем в виду представителей 9 класса по ISCO-08 (уборщицы, составляющие в нем почти половину, а также грузчики, упаковщики, разнорабочие в строительстве и на фермах). Как видно из таблицы 1, эта группа заметно старше, чем квалифицированные рабочие или все работающее население страны.

Рассмотрим теперь квалифицированных рабочих, под которыми мы подразумеваем представителей 7 и 8 классов по ISCO-08. В 7 класс входят представители ручного труда (сварщики, механики, электрослесари, электрики, штукатуры, строители домов, плотники, токари, портные). К 8 классу относятся операторы машин и механизмов, включая водителей транспортных средств, составляющих свыше 80 \% этого класса. Из других массовых групп в 8-м классе можно назвать операторов станков, машинистов кранов и др. Как видно из таблицы 1, в возрастной когорте 26-35 лет их численность больше, чем в возрастных когортах 36-45 лет или 46-55 лет. Более того, существенных возрастных различий между квалифицированными рабочими ручного труда и операторами машин и механизмов в этом отношении нет: если среди первых доля молодежи до 35 лет составляет 37,7\%, а лиц в возрасте от 56 лет и старше - 14,2\%, то среди вторых эти показатели выглядят как 33,0\% и 14,4\%. Таким образом, проблема «кадрового голода» российской промышленности заключается не в том, что молодежь вообще «не идет» в квалифицированные рабочие, а в том, что она реже представителей старшего поколения идет работать 
рабочими на промышленные предприятия, находящиеся в собственности у государства,- на таких предприятиях работает менее четверти рабочих до 35 лет, а среди тех, кому 56 лет и более, таких почти половина. В результате рабочая молодежь оказывается зачастую вне зоны внимания статистических органов, и не случайно доля официально оформленной по месту работы рабочей молодежи $(70,8 \%)$ заметно меньше, чем в старшем поколении рабочих $(83,4)$.

Таблица 1

\section{Возрастная структура различных профессиональных групп} и работающих в целом, \%*

\begin{tabular}{|c|c|c|c|c|c|c|c|}
\hline Группы & 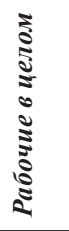 & 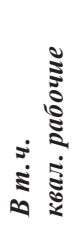 & 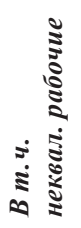 & 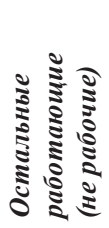 & 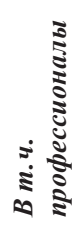 & 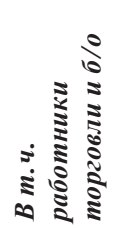 & 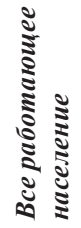 \\
\hline $18-25$ лет & 7,5 & 7,6 & 6,4 & 9,6 & 8,5 & 13,6 & 8,9 \\
\hline 26-35 лет & 26,5 & 27,8 & 20,4 & 27,0 & 26,6 & 23,9 & 26,8 \\
\hline 36-45 лет & 25,4 & 26,4 & 22,7 & 25,6 & 26,2 & 24,1 & 25,5 \\
\hline $46-55$ лет & 23,6 & 24,0 & 24,7 & 21,2 & 20,3 & 20,7 & 22,0 \\
\hline 56-65 лет & 14,7 & 13,1 & 19,3 & 14,1 & 14,5 & 14,8 & 14,3 \\
\hline От 66 лет & 2,4 & 1,2 & 6,4 & 2,4 & 3,9 & 2,8 & 2,4 \\
\hline \multicolumn{8}{|c|}{ Справочно: возраст } \\
\hline Средний & 42,5 & 41,7 & 45,6 & 41,6 & 42,3 & 41,4 & 41,9 \\
\hline Медианный & 42 & 41 & 46 & 41 & 41 & 41 & 41 \\
\hline
\end{tabular}

* Серым фоном в таблицах здесь и далее применительно к отдельным профессиональным группам выделены значения, которые больше аналогичных показателей по работающим в целом более чем на $3 \%$, а темным фоном - значения, которые меньше аналогичных показателей по работающим в целом более чем на $3 \%$.

Отчасти возрастная асимметрия по типам собственности предприятий, где занята рабочая молодежь, связана с отраслевой принадлежностью этих предприятий ${ }^{1}$. Рабочие от 56 лет и старше чаще работают в отраслях социальной сферы (образование, здравоохранение, культура), ЖКХ и сельском хозяйстве. Рабочих до 35 лет включительно относительно чаще

\footnotetext{
${ }^{1}$ Массив РМЭЗ НИУ ВШЭ не является репрезентативным по отраслям, поэтому к приводимым цифрам надо относиться с осторожностью. Однако эти тенденции прослеживаются и на массивах данных за другие годы, что говорит об их реальности и при дискуссионности оценки их масштабов.
} 
можно встретить в строительстве, торговле, легкой и пищевой промышленности (рис. 1). В остальных отраслях четко выраженной возрастной асимметрии не прослеживается. При этом если концентрацию рабочих старшего поколения в отраслях социальной сферы или ЖКХ можно объяснить относительно более легким в плане физических нагрузок трудом в них, а в сельском хозяйстве - возрастными диспропорциями поселенческой структуры, то довольно сложно понять, почему молодежь шире представлена в легкой и пищевой промышленности, а не в ВПК при близком уровне заработной платы (в среднем 23395 руб. на первых и 25408 руб. на вторых в 2016 г. по данным РМЭЗ НИУ ВШЭ). Таким образом, молодежь все еще традиционно достаточно массово идет «в рабочие», но при этом относительно чаще оказывается вне зоны основного спроса на них в условиях возрождения системы ВПК.

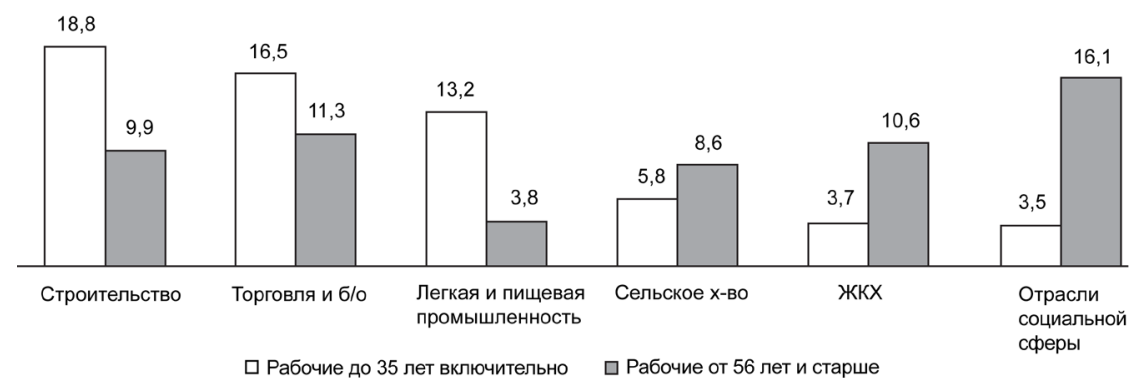

Puc. 1. Отраслевая локализация рабочих младших и старших возрастных когорт, \% (отрасли укрупнены)

В то же время нельзя утверждать, что в этой области не происходит никаких изменений и сентенции о нежелании молодежи «идти в рабочие» полностью лишены оснований. По возрастной структуре разных профессиональных групп (табл. 1) видно, что россияне в возрасте до 25 лет однозначно предпочитают профессии продавца или работника сферы бытового обслуживания рабочим профессиям. Причины этого уже освещались в литературе (Кремнева, Лукьянова 2015; Тартаковская, Ваньке 2016), поэтому специально останавливаться на них не будем. Отметим лишь, что хотя эти предпочтения и начали формироваться еще в 1990-е гг., действительно значимый масштаб они приобрели в 2010-е гг.- в возрастной когорте до 25 лет продавцов среди молодежи стало больше, чем рабочих.

\section{Здоровье российских рабочих}

Здоровье работающего населения страны в целом выглядит весьма неоднозначно. С одной стороны, среди работающих россиян в возрасте от 18 лет и старше насчитывается лишь менее половины (40,0\%) людей 
без диагностированных хронических заболеваний. При этом хронические заболевания 1-2-го типа имеют 34,8 \% работающего населения, а остальные - хронические заболевания трех и более типов. С другой стороны, и среди работающего населения страны в целом, и среди рабочих в частности, инвалидность как признак частичной утраты трудоспособности встречается довольно редко. Так, среди рабочих инвалидность имеют $1,6 \%$, а у остального работающего населения - 2,6\%. Таким образом, подавляющее большинство работающего населения страны не имеет признанных системой здравоохранения ограничений трудоспособности, хотя лишь немногим более трети могут рассматриваться как здоровые.

Таблица 2

Показатели наличия хронических заболеваний у рабочих и остальных работающих, \%

\begin{tabular}{|c|c|c|c|c|c|c|c|}
\hline $\begin{array}{c}\text { Число типов } \\
\text { хрон. заболеваний }\end{array}$ & 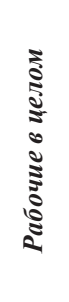 & 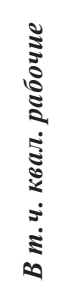 & 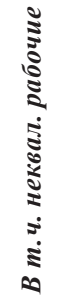 & 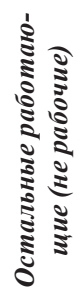 & 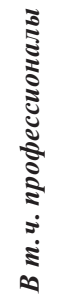 & 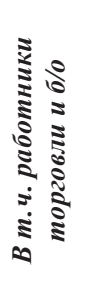 & 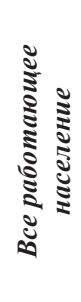 \\
\hline \multicolumn{8}{|c|}{ Все хронические заболевания } \\
\hline $\begin{array}{l}\text { Нет таких заболева- } \\
\text { ний }\end{array}$ & 34,7 & 40,5 & 30,0 & 41,0 & 38,3 & 41,7 & 40,0 \\
\hline $1-2$ & 36,8 & 36,5 & 36,3 & 34,8 & 35,0 & 32,6 & 34,3 \\
\hline 3 и более & 28,5 & 23,0 & 33,7 & 24,2 & 26,7 & 25,7 & 25,7 \\
\hline \multicolumn{8}{|c|}{ Хронические заболевания, значительно повышающие риск инвалидизации } \\
\hline $\begin{array}{l}\text { Нет таких заболева- } \\
\text { ний }\end{array}$ & 61,5 & 64,0 & 50,5 & 55,4 & 52,3 & 41,7 & 57,3 \\
\hline $1-2$ & 28,7 & 27,4 & 34,0 & 30,9 & 33,2 & 32,6 & 30,3 \\
\hline 3 и более & 9,8 & 8,6 & 15,5 & 13,7 & 14,5 & 25,7 & 12,4 \\
\hline
\end{tabular}

Судя по данным РМЭЗ НИУ ВШЭ, квалифицированные рабочие, а за счет них - и рабочие в целом, отличаются по крайней мере не худшим здоровьем, чем остальные работающие (табл. 2). Так, хотя хронические заболевания встречаются у рабочих несколько чаще, чем по остальным работающим, среди квалифицированных рабочих и остального работающего населения эти показатели совпадают с точностью до полупроцента. Кроме того, среди квалифицированных рабочих реже встречаются заболевания, 
значительно (т.е. более чем в полтора раза) повышающие риски получения инвалидности в трудоспособном возрасте. В то же время у неквалифицированных рабочих по всем показателям здоровья самые худшие индикаторы среди всех профессиональных групп. Помимо показателей, приведенных в таблице 2, это относится и к доле имеющих инвалидность $(3,4 \%)$, которая примерно вдвое выше, чем у квалифицированных рабочих, а также к самооценкам своего здоровья.

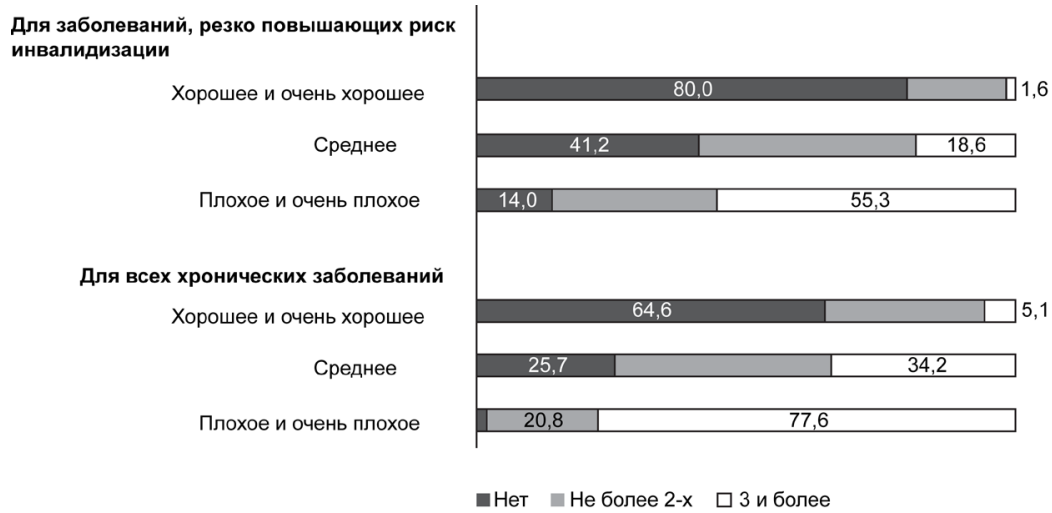

Puc. 2. Число диагностированных хронических заболеваний у работающих из групп с разной самооценкой своего здоровья, \%

Тенденция меньшей распространенности среди квалифицированных рабочих, а за счет них и рабочих в целом, наиболее опасных с точки зрения рисков инвалидизации типов хронических заболеваний сохраняется и при анализе отдельных возрастных когорт. Такого рода заболевания отсутствуют у $80,1 \%$ рабочих и 73,1\% остального работающего населения страны в возрасте 26-35 лет, 67,3\% и 60,0\% в возрасте 36-45 лет, 51,6\% и 40,1 \% в возрасте 46-55 лет. В то же время в возрастной когорте 56-65 лет эти показатели почти выравниваются и составляют уже около 30\%, а среди лиц старше 65 лет - около $20 \%$. Некоторое преимущество рабочих сохраняется и в старших возрастах: так, лишь треть (33,3\%) рабочих при 48,3\% среди остальных работающих в возрасте от 66 лет и старше имеют три и более хронических заболевания, значительно повышающих риски инвалидизации.

Отчасти на такое положение влияет гендерная асимметрия различных профессиональных групп: среди рабочих мужчины составляют 75,0 \% (в том числе среди квалифицированных рабочих - 85,6\%), в то время как среди остальных работающих - всего $33,5 \%$. Российские мужчины в силу специфики понимания мужественности в отечественной культуре традиционно в меньшей степени готовы заниматься своим здоровьем и жаловаться на него, в том числе обращаясь к врачам (Manning, Tikhonova 2008). 
Если бы гендерная структура рабочих и остальных работающих была одинаковой и состояла бы поровну из мужчин и женщин, то доля не имеющих хронических заболеваний, значительно повышающих риски инвалидизации, была бы идентичной: 57,0 \% у рабочих и 57,1 \% у остального российского населения. Кроме того, среди российских мужчин в последние годы наметился «слом» традиционной модели отношения к своему здоровью. В итоге молодые мужчины-рабочие стали уделять больше внимания здоровью (Каравай 2016). Что касается готовности признать проблемы со здоровьем, то и среди мужчин, и среди женщин по достижении ими возрастного рубежа в 45 лет можно встретить жалующихся на свое состояние с равной вероятностью.

\section{Субъективные самооценки здоровья В различных профессиональных группах}

Несмотря на то, что самооценка здоровья далеко не всегда совпадает с его формальными показателями, в целом они довольно тесно связаны между собой (рис. 3) ${ }^{1}$. При этом с точки зрения состава (на 72,6\%) группа жалующихся на плохое здоровье состоит из людей старше 45 лет и на две трети $(66,8 \%)$ это женщины. Рассмотрим теперь самооценку здоровья рабочими в целом и отдельными их подгруппами. Как видно из таблицы 3 , оценки различаются у неквалифицированных и квалифицированных рабочих: если первые более чем в двух третях случаев говорят, что здоровье у них «среднее», то квалифицированные рабочие, наоборот, демонстрируют максимальную из всех профессиональных групп распространенность удовлетворенности своим здоровьем. Эта тенденция сохраняется в других подгруппах рабочих. Так, самооценки здоровья у рабочих квалифицированного ручного труда и операторов машин и механизмов практически совпадают (разница менее $1 \%$ по всем позициям), в то время как у неквалифицированных рабочих - отличаются в 1,5-2 раза.

Если говорить о влиянии гендерного фактора, то для мужчин и женщин, занятых квалифицированным ручным трудом, удовлетворенность здоровьем высока и практически одинакова: 49,7 \% мужчин и 49,5 \% женщин оценивают его как хорошее и очень хорошее. Среди работающих с машинами и механизмами мужчины несколько чаще женщин хорошо оценивают свое здоровье (50,1\% и 40,0\% соответственно). Сильнее всего сказывается гендер на самооценке здоровья у неквалифицированных рабочих: лишь 23,1 \% женщин при 41,9\% мужчин в этой группе оценивают свое здоровье как хорошее и очень хорошее. Сильно дифференцирует оценки внутри разных групп рабочих и возраст (рис. 3).

\footnotetext{
1 Тесная связь этих переменных прослеживается и при статистической проверке. Так, коэффициент Спирмена для них составлял в использованном массиве 0,589.
} 


\section{Таблица 3}

Оценки представителями различных профессиональных групп и работающих в целом своего здоровья (кроме затруднившихся ответить), \%

\begin{tabular}{|c|c|c|c|c|c|c|c|}
\hline Оценки & 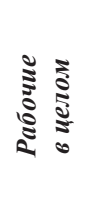 & 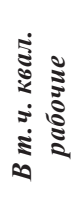 & 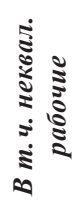 & 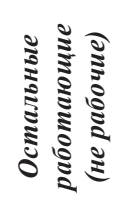 & 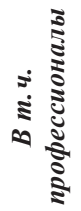 & 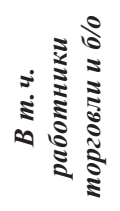 & 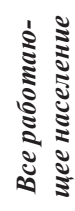 \\
\hline $\begin{array}{l}\text { Хорошее } \\
\text { и очень } \\
\text { хорошее }\end{array}$ & 45,9 & 49,2 & 30,9 & 43,8 & 44,0 & 41,7 & 44,3 \\
\hline Среднее & 49,9 & 47,0 & 62,6 & 51,4 & 51,8 & 52,2 & 51,0 \\
\hline $\begin{array}{l}\text { Плохое } \\
\text { и очень плохое }\end{array}$ & 3,6 & 3,1 & 5,7 & 4,2 & 3,6 & 5,3 & 4,0 \\
\hline
\end{tabular}

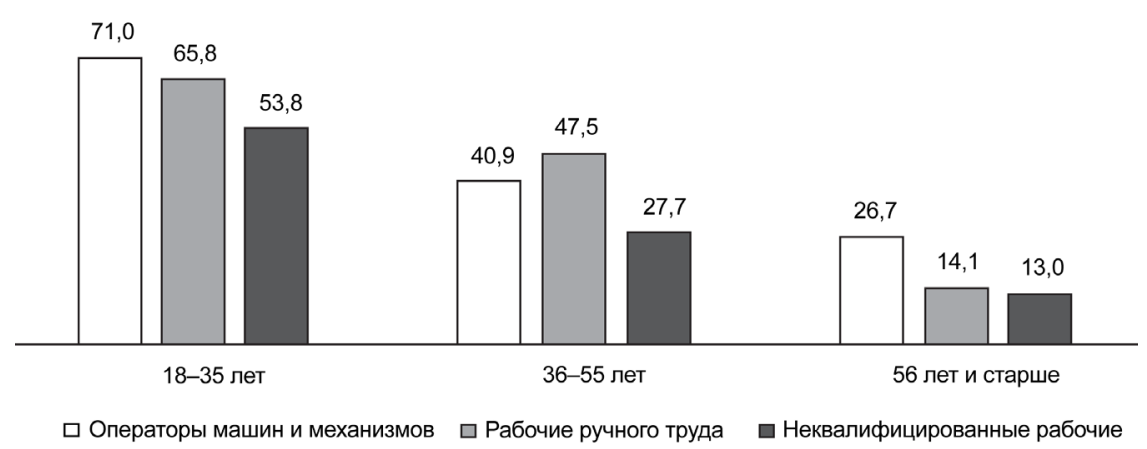

Рис. 3. Доля оценивающих свое здоровье как хорошее и очень хорошее среди рабочих разного возраста в различных профессиональных группах, \%

Если совместить гендерный и возрастной срезы анализа, то оказывается, что даже в возрастной группе до 35 лет и мужчины, и женщины на рабочих местах неквалифицированного физического труда характеризуются относительно худшим здоровьем, чем остальные рабочие и работающее население страны в целом. При этом женщинами оно уже в молодости оценивается хуже, чем мужчинами. В средних возрастах здоровье ухудшается и у тех, и у других, но у женщин этот процесс идет быстрее. Так, если среди женщин из числа неквалифицированных рабочих как о хорошем о своем здоровье говорит лишь каждая пятая, то у мужчин - каждый третий. Наконец, в пенсионном возрасте на рабочие места неквалифицированного физического труда женщин заставляет выходить, видимо, только нужда, т.к. лишь каждая десятая из них в этом возрасте характеризует свое здоровье как хорошее (у мужчин этот показатель вдвое выше). 


\section{Дискуссия}

Возрастная структура российских рабочих в целом и квалифицированных рабочих в частности совпадают с возрастной структурой работающего населения страны. При этом, хотя для группы до 25 лет можно зафиксировать некоторые изменения в их предпочтениях при выборе видов профессиональной деятельности по отношению к традиционным для российской молодежи, эти изменения пока не сказываются всерьез на возрастной структуре квалифицированных рабочих. В то же время для неквалифицированных рабочих характерна специфическая возрастная структура, свидетельствующая о серьезных изменениях в последние годы в предпочтениях молодежи при выборе карьерных траекторий и массовом нежелании идти на такие рабочие места. Вместо неквалифицированного труда молодежь предпочитает идти «в торговлю». Что касается рабочих мест квалифицированного труда, то молодежь идет на них достаточно охотно, но относительно чаще выбирает не те, где можно получать высокие зарплаты лишь после многих лет приобретения опыта и профессиональных знаний (например, ВПК или тяжелая промышленность), а те, которые характеризуются более высокими заработками сразу, даже в ущерб социальной защищенности (например, строительство). В результате значительная часть рабочей молодежи вообще не попадает в систему статистического учета.

Как анализ распространенности инвалидности и хронических заболеваний разного типа, так и анализ оценок российскими рабочими своего здоровья свидетельствуют, что это очень гетерогенная по состоянию здоровья профессиональная группа. Квалифицированные рабочие, независимо от пола, возраста и характера своего труда, характеризуются хорошими показателями здоровья, в целом не уступающими показателям профессионалов с высшим образованием. В то же время работники неквалифицированного физического труда характеризуются не только относительно худшими показателями здоровья во всех возрастных группах, но и наиболее выраженной тенденцией его ухудшения с возрастом. Это ухудшение имеет яркую гендерную асимметрию (женщины находятся в этой группе в гораздо худшем положении, чем мужчины).

С учетом всех рассмотренных в статье показателей здоровья можно говорить о трех группах работников, различающихся этим компонентом их человеческого потенциала: (1) полностью здоровых; (2) с наличием отдельных проблем со здоровьем; (3) с множественными и серьезными проблемами со здоровьем. Эти группы по-разному представлены в разных подгруппах рабочих. Так, полностью здоровыми можно считать лишь немногим более трети рабочих в целом, но около $40 \%$ квалифицированных рабочих и лишь $25 \%$ неквалифицированных рабочих (при трети среди всего работающего населения страны). Доля тех, кто имеет отдельные проблемы со здоровьем, составляет около половины во всех профессиональных 
группах, за исключением неквалифицированных рабочих, у которых она на 6-7\% выше. Остальные имеют множественные и серьезные проблемы со здоровьем. Эти цифры свидетельствуют о том, что физиологический ресурс квалифицированных рабочих по-прежнему достаточно высок для выполнения задач, связанных с интенсивной технологической перестройкой экономики. Тем не менее у неквалифицированных рабочих ситуация обстоит иначе. Даже в молодых возрастных группах их здоровье заметно хуже, чем у других профессионалов.

\section{Заключение}

В плане совершенствования государственной социальной политики как главного инструмента формирования человеческого потенциала вышесказанное позволяет сделать несколько выводов. Прежде всего, можно зафиксировать наличие «системного сбоя» в системе здравоохранения, при котором плохое здоровье не позволяет многим людям ни получить медицинскую помощь, способствующую его восстановлению даже в молодом и среднем возрасте, что снижает общий трудовой потенциал человека, ни оформить инвалидность.

Кроме того, из результатов нашего анализа понятно, что в случае реализации планов по лишению возможностей использования государственной системы здравоохранения лиц без оплаты страховых взносов в ОМС в первую очередь пострадают неквалифицированные рабочие. Это обусловлено тем, что четверть этой группы не имеет официальной занятости, а следовательно - за них не проводятся отчисления в ОМС. При этом именно у них самые низкие из всех профессиональных групп доходы, что лишает их возможности прибегнуть к услугам платного здравоохранения.

Наконец, что касается пенсий, то низкий уровень официальной занятости среди неквалифицированных рабочих и отсутствие к моменту достижения ими пенсионного возраста достаточного для получения пенсии числа пенсионных баллов вынудят многих использовать систему инвалидности (с учетом их относительно худшего, чем в других профессиональных группах здоровья) или социальную пенсию, что приведет к росту численности бедных. Для преодоления этой коллизии можно рассмотреть, в частности, такую меру как введение разного (с дифференциацией, например, в 3-5 лет) возраста выхода на пенсию для лиц физического (при условии занятости им в течение не менее чем 10 лет перед наступлением пенсионного возраста) и нефизического труда. Альтернативой могла бы выступить такая мера как повышение пенсионного возраста (по аналогии с тем, как был повышен возраст выхода на пенсию для госслужащих) только для лиц нефизического труда.

Если говорить о политике занятости в части привлечения молодежи в систему ВПК и тяжелую промышленность, то необходима разработка целевой 
программы привлечения в эти отрасли молодых рабочих кадров. Это могли бы быть, например, особые жилищные программы для рабочей молодежи по аналогии с теми, которые действуют для молодых ученых. Одновременно необходимо организовывать специальные курсы переподготовки и повышения квалификации для молодых рабочих, готовых при определенных условиях перейти на предприятия другой отрасли со сменой профессии.

Определенных изменений требует, судя по анализу здоровья и возрастной структуры рабочих, и миграционная политика. По составу различных профессиональных групп видно, что единственная группа, численность которой от поколения к поколению сокращается при неизменности ее общей численности в профессиональной структуре российской экономики - это неквалифицированные рабочие. В этих условиях массовый прием мигрантов извне может быть оправдан в случае, если они готовы занимать эти рабочие места. В то же время неквалифицированная рабочая сила обычно плохо интегрируется в принимающее общество, в отличие от людей с хорошей языковой и образовательной подготовкой.

Таким образом, анализ человеческого потенциала российских рабочих в части такого компонента их человеческого потенциала как физиологический ресурс свидетельствует о том, что в этой области доминируют традиционные для этой профессиональной группы тенденции, обеспечивающие в целом относительно благополучную ситуацию. Однако происходящие в среде рабочих изменения говорят о возникновении и нарастании в российском обществе ряда требующих повышенного внимания вызовов для государственной социальной политики, причем даже не столько в отношении собственно физиологического ресурса рабочих, сколько в тесно связанных с ним других сферах жизни социума.

\section{Выражение благодарности}

Статья подготовлена в рамках работы по проекту РФФИ № 16-03-00098-ОГН.

\section{Список источников}

Авдошина Н.В. (2003) Социологический анализ трудового потенциала современных промышленных предприятий. II Всероссийский соииологический конгресс «Российское общество и сочиология в ХХІ веке: сочиальные вызовы и альтернативы». М.: Альфа-М:4472-4477.

Аникин В.А. (2017) Человеческий капитал: становление концепции и основные трактовки. Экономическая соичиология, 4 (18): 120-156.

Бессокирная Г.П. (2013) Влияние здоровья рабочих на их трудовую деятельность и свободное время. Общество и здоровье: современное состояние и тенденции развития. М.: РОС: 143-153.

Заславская Т.И. (2002) Социетальная трансформаџия российского общества: Деятельностно-структурная концепциия. М.: Дело. 
Каравай А.В. (2016) Отношение российских рабочих к своим ресурсам: финансам, здоровью и свободному времени. Журнал исследований социальной политики, 2 (14): 229-244.

Кремнева Н., Лукьянова Е. (2015) Рабочая профессия: успех или неудача? Восприятие социального положения рабочего в семейном контексте. Интер, (10):26-38.

Кузьмич О.С. (2012) Состояние здоровья населения России. П. М. Козырева (ред.). Вестник Российского мониторинга экономического положения и здоровья населения HИУ ВШЭ (RLMS-HSE). Вып. 2. М.: Издательский дом НИУ ВШЭ: 170-211.

Латова Н.В. (2017) Роль профессионального образования в воспроизводстве российского рабочего класса. Общественные науки и современность, (1): 99-113.

Митягина Е.В. (2014) Ресурсы российских рабочих в условиях современных модернизационных прочессов. Нижний Новгород: НИСОЦ.

Назарова И.Б. (2007) Здоровье занятого населения. М.: Издательство МГУ.

Плискевич Н. М. (2012) Человеческий капитал в трансформирующейся России. М.: ИЭ РАН.

Соболева И.В. (2009) Парадоксы измерения человеческого капитала. М.: ИЭ РАН.

Тартаковская И.Н., Ваньке А. В. (2016) Карьера рабочего как биографический выбор. Социологическое обозрение, 3 (15): 9-48.

Тихонова Н.Е., Каравай А.В. (2017) Человеческий капитал российских рабочих: общее состояние и специфические особенности. Мир России, 3 (26): 6-35.

Шкаратан О. И., Мэннинг Н., Тихонова Н.Е., Давыдова Н. М., Сидорина Н. Ю. (2003) Государственная социальная политика и стратегия выљивания домохозяйств. М.: Издательский дом ГУ-ВШЭ.

Baldock J., Mitton L., Manning N., Vickerstaff S. (ed.) (2007) Social policy. Oxford: Oxford University Press.

Becker G. S. (1962) Investment in Human Capital: A Theoretical Analysis. The Journal of Political Economy, 5 (70): 9-49.

Manning N., Tikhonova N. (ed.) (2008) Health and Health Care in the New Russia. London: Ashgate.

Mincer J. (1958) Investment in Human Capital and Personal Income Distribution. The Journal of Political Economy, 4 (66):281-302.

Sen A. (1999) Development as Freedom. Oxford: Oxford University Press. 
Natalia Tikhonova

\section{THE HEALTH AND AGE STRUCTURE OF RUSSIAN WORKERS: TRADITION AS OPPOSED TO CHANGE}

The article examines an important element of workers' human potential: their physiological resources, which are operationalized through indicators of age and health, such as the presence of disabilities, twenty-three types of chronic diseases and self-assessments of health. What is shown is that the age structure of Russian workers traditionally reproduces itself and practically coincides with the age structure of the working population of the country in general. This means we cannot fix a clear deterioration of the human potential of workers in this respect in recent decades. The myth that young people do not want to become workers is mainly due to the high proportion of informal employment among young workers. However, during the last years there have been some changes in this regard: among young people under twenty-five the occupation of the salesperson has actually become more popular than the occupation of worker. It is also shown that Russian workers are a very heterogeneous professional group in terms of their health. While skilled workers are characterized by good health indicators, unskilled manual workers have the worst health indicators of all occupational groups even in their youth; they are also characterized by the most prominent tendency of its further deterioration with age, and this deterioration has a clear gender asymmetry. Three groups of workers are defined: 1) completely healthy; 2) with some health problems; 3) having multiple and serious health problems. In this paper, estimates of their shares and distribution in different subgroups of workers are presented. The key conclusion is that the physiological resources of qualified workers in Russia are now sufficient to fulfill the tasks facing them in the event of possible future intensive technological restructuring of the economy.

Keywords: Workers, health, age structure, human potential, human capital, traditions

DOI: $10.17323 / 727-0634-2018-16-2-311-326$

\section{References}

Anikin V.A. (2017) Chelovecheskiy kapital: stanovlenie kontseptsii i osnovnye traktovki [Human Capital: Development of the Concept and Common Interpretations]. Ekonomicheskaya sotsiologiya [Economic Sociology], 4 (18): 120-156.

Avdoshina N.V. (2003) Sociologicheskij analiz trudovogo potenciala sovremennyh promyshlennyh predprijatij [Sociological Analysis of the Labor Potential of Modern Industrial Enterprises]. II Vserossijskij sociologicheskij kongress 'Rossijskoe obshhestvo i sociologija v XXI veke: social'nye vyzovy i al 'ternativy'. [II Russian Sociological Congress 'Russian Society and Sociology in the $21^{\text {st }}$ Century: Social Challenges and Alternatives']. Moscow: Al'fa-M: 4472-4477.

Natalia E. Tikhonova - Dr. Sci. (Sociol.), Professor-researcher, National Research University Higher School of Economics; Chief Researcher, Federal Center of Theoretical and Applied Sociology of the Russian Academy of Sciences, Moscow, Russian Federation. Email: ntihonova@hse.ru 
Baldock J., Mitton L., Manning N., Vickerstaff S. (eds.) (2007) Social Policy. Oxford: Oxford University Press.

Becker G. S. (1962) Investment in Human Capital: A Theoretical Analysis. The Journal of Political Economy, 5 (70): 9-49.

Bessokirnaya G. P. (2013) Vliyanie zdorov'ya rabochikh na ikh trudovuyu deyatel'nost' i svobodnoe vremya [The Effect of Workers' Health on Their Work and Leisure Time]. Obshchestvo i zdorov'e: sovremennoe sostoyanie i tendentsii razvitiya [Society and Health: Current Status and Development Trends]. Moscow: ROS: 143-153.

Karavay A. V. (2016) Otnoshenie rossiyskikh rabochikh k svoim resursam: finansam, zdorov'yu i svobodnomu vremeni [The attitude of Russian Workers to Their Resources: Finance, Health and Free Time]. Zhurnal issledovanii sotsial'noy politiki [The Journal of Social Policy Studies], 2 (14): 229-244.

Kremneva N., Luk'yanova E. (2015). Rabochaya professiya: uspekh ili neudacha? Vospriyatie sotsial'nogo polozheniya rabochego v semeynom kontekste [Working Profession: Success or Failure? Perception of the Social Status of the Worker in a Family Context]. Inter [Inter], 10:26-38.

Kuz'mich O.S. (2012) Sostoyanie zdorov'ya naseleniya Rossii [The State of Health of the Population of Russia]. P. M. Kozyreva (ed.). Vestnik Rossiyskogo monitoringa ekonomicheskogo polozheniya i zdorov'ya naseleniya NIU VShE (RLMS-HSE) [Bulletin of the Russian Monitoring of the Economic Situation and Public Health of the Higher School of Economics (RLMS-HSE)], Vol. 2. Moscow: Izdatel'skiy dom NIU VShE: 170-211.

Latova N. V. (2017) Rol' professional'nogo obrazovanija v vosproizvodstve rossijskogo rabochego klassa [The Role of Vocational Education in the Reproduction of the Russian Working Class]. Obshhestvennye nauki i sovremennost' [Social Sciences and Modernity], (1):99-113.

Manning N., Tikhonova N. (ed.) (2008) Health and Healthcare in the New Russia. London: Ashgate.

Mincer J. (1958) Investment in Human Capital and Personal Income Distribution. The Journal of Political Economy, 4 (66): 281-302.

Mityagina E. V. (2014) Resursy rossiyskikh rabochikh v usloviyakh sovremennykh modernizatsion-nykh protsessov [Resources of Russian Workers in the Conditions of Modern Modernization Processes]. Nizhniy Novgorod: NISOTs.

Nazarova I. B. (2007) Zdorov'e zanyatogo naseleniya [Health of the Employed Population]. Moscow: Izdatel'stvo MGU.

Pliskevich N. M. (2012) Chelovecheskiy kapital v transformiruyushcheysya Rossii [Human Capital in a Transforming Russia]. Moscow: IE RAN.

Sen A. (1999) Development as Freedom. Oxford: Oxford University Press.

Shkaratan O. I., Manning N., Tikhonova N.E., Davydova N. M., Sidorina N. Ju. (2003) Gosudarstvennaja social'naja politika i strategija vyzhivanija domohozjajstv [State Social Policy and Strategy for the Survival of Households]. M.: Izdatel'skij dom GU-VShJe.

Soboleva I. V. (2009) Paradoksy izmereniya chelovecheskogo kapitala [Paradoxes of Measuring Human Capital]. Moscow: IE RAN.

Tartakovskaya I.N., Van'ke A.V. (2016) Kar'era rabochego kak biograficheskiy vybor [The Career of the Worker as a Biographical Choice]. Sotsiologicheskoe obozrenie [Sociological Review], 3 (15): 9-48.

Tikhonova N.E., Karavay A. V. (2017) Chelovecheskiy kapital rossiyskikh rabochikh: obshchee sostoyanie i spetsificheskie osobennosti [The Human Capital of the Russian workers: The General Status and Specific Features]. Mir Rossii [The Universe of Russia]. 3 (26): 6-35.

Zaslavskaja T. I. (2002) Societal'naja transformacija rossijskogo obshhestva: Dejatel'nostnostrukturnaja koncepcija [Societal Transformation of Russian Society: The Activity-structural Concept]. Moscow: Izd-vo 'Delo'. 